\title{
Pathologic analysis of glioblastoma via multiple stereotactic biopsies of active tumor and necrosis
}

\author{
TAE-YOUNG JUNG ${ }^{1,5}$, SHIN JUNG ${ }^{1,5}$, IN-YOUNG KIM ${ }^{1,5}$, KYUNG-SUB MOON ${ }^{1,5}$, WOO-YOUL JANG ${ }^{1}$, \\ SEUNG-JIN PARK ${ }^{2}$, YOUNG-HEE KIM ${ }^{5}$, HYUNG-SEOK KIM ${ }^{3}$, JUNG-JOON MIN ${ }^{4}$ and JAHAE KIM ${ }^{4}$ \\ Departments of ${ }^{1}$ Neurosurgery, ${ }^{2}$ Biomedical Engineering, ${ }^{3}$ Pathology and ${ }^{4}$ Nuclear Medicine, and ${ }^{5}$ Brain Tumor \\ Research Laboratory, Chonnam National University Research Institute of Medical Sciences, Chonnam \\ National University Hwasun Hospital and Medical School, Gwangju, Republic of Korea
}

Received August 11, 2011; Accepted October 3, 2011

DOI: $10.3892 /$ or.2011.1522

\begin{abstract}
To obtain more representative biopsy specimens in glioblastoma, we performed multiple stereotactic biopsies of active tumor and necrosis. We investigated their pathologic differences of diagnosis and also examined the pathologic features that varied with ${ }^{11} \mathrm{C}$-methionine uptake on PET. From December 2009 to October 2010, we performed stereotactic biopsies in 12 patients with radiologically heterogeneous, ringenhanced lesions. We biopsied the MR enhanced lesions for active tumor and the MR non-enhanced lesions for necrosis and analyzed differences of pathologic diagnoses between them. As correlating factors of the degree of ${ }^{11} \mathrm{C}$-methionine uptake ( $\mathrm{T} / \mathrm{N}$ ratio), the pathologic findings, including cell density, Ki-67 LI, microvessel density, number of endothelial proliferations, the immunopositivity for L-amino acid transporter 1 (LAT1) were analyzed. The final diagnosis of each specimen was glioblastoma. The diagnostic failure rate was $33.3 \%$ (4/12 patients) when we selected only active tumors and $40 \%$ (4/10 patients) when we selected necrotic lesions. The $\mathrm{T} / \mathrm{N}$ ratio showed a statistical correlation with cell density depending on the degree of necrosis and LAT1 immunopositivity ( $\mathrm{P}=0.002$ and 0.032$)$. LAT1 was localized in the tumor cells, vascular endothelium, and the vicinity of endothelial proliferation. Multiple stereotactic biopsies of active tumor and necrosis could provide the diagnostic yield in glioblastoma. The ${ }^{11} \mathrm{C}$-methionine uptake mostly reflected cell densities depending on the degree of necrosis.
\end{abstract}

\section{Introduction}

Stereotactic brain biopsy is a minimally invasive form of diagnostic technique that uses a three-dimensional coordinate

Correspondence to: Dr Tae-Young Jung, Department of Neurosurgery, Chonnam National University Hwasun Hospital, 160 Ilsim-ri, Hwasun-eup, Hwasun-gun, Jeollanam-do 519-809, Republic of Korea

E-mail: jung-ty@chonnam.ac.kr

Key words: biopsy, ${ }^{11} \mathrm{C}-\mathrm{methionine} \mathrm{PET}$, enhanced MRI, glioblastoma, LAT1, stereotactic system to locate small targets inside the brain. Magnetic resonance imaging (MRI) provides sharp anatomical details of the pathologic brain and stereotactic operations generally use MRI. However, an inaccurate diagnosis or underestimation of a lesion's pathological grade sometimes occur because clinicians can get only a small amount of tissue to represent the lesion's total features (1-3). Even if the clinician has a provisional radiological diagnosis of high-grade glioma, the pathologist may confirm a low-grade glioma from the small specimen. Gliomas, especially, are histologically heterogeneous, and inadequate localization of the stereotactic biopsy may produce specimens that are irrelevant for identifying and grading the lesions (4). Endothelial proliferation and/or necrosis are essential diagnostic features for the pathological diagnosis of glioblastoma. On enhanced MR images, an enhanced lesion corresponds to a cellular, highly vascularized area of the neoplasm and a non-enhanced lesion corresponds to a necrotic or cystic lesion, with decreased vasculature (5). Therefore, to obtain more representative biopsy specimens, we biopsied the MR enhanced lesions for active tumor and the MR non-enhanced lesions for necrosis to cover the important pathologic features and investigated their pathologic differences of diagnosis.

${ }^{11} \mathrm{C}$-methionine uptake is regulated by an amino acid transporter at the endothelium surface, and L-type amino acid transporter 1 (LAT1) is a major route for the transport of large neutral amino acids, including methionine $(6,7)$. This uptake reflects the tumor cell density, proliferative potential and angiogenic capability of gliomas (8-11). We also examined the pathologic features that varied with ${ }^{11} \mathrm{C}$-methionine uptake.

\section{Materials and methods}

Patients and stereotactic biopsy. From December 2009 to October 2010, we performed stereotactic biopsies in 12 patients who had radiologically high-grade gliomas at Chonnam National University Hwasun Hospital. To determine locations for the tumor biopsies, we employed contrast-enhanced T1-weighted images. ${ }^{11} \mathrm{C}$-methionine PET was also performed. To obtain tissue with high diagnostic value, we aimed in each case for the active lesion, contrast-enhanced area on MRI; to obtain the necrotic lesion, we targeted a non-enhanced area 
(Fig. 1A and C). Three to four core biopsies were taken from each target. Two patients underwent biopsy of a single area because of bleeding. However, there was no significant bleeding due to increased intracranial pressure. A Leksell stereotactic apparatus guided the biopsy, under local anesthesia.

${ }^{11} \mathrm{C}$-methionine positron emission tomography. The $\left[{ }^{11} \mathrm{C}\right] \mathrm{CO}_{2}$ was produced by irradiating $\mathrm{N}_{2}$ gas with $16.4 \mathrm{MeV}$ protons accelerated in a cyclotron (General Electric, USA). $\left[{ }^{11} \mathrm{C}\right] \mathrm{CO}_{2}$ was converted to $\left[{ }^{11} \mathrm{C}\right] \mathrm{CH}_{4}$ using nickel, under hydrogen gas and subsequently converted to $\left[{ }^{11} \mathrm{C}^{-} \mathrm{CH}_{3} \mathrm{I}\right.$ by reacting it with Iodogen. Finally, the $\left[{ }^{11} \mathrm{C} \mathrm{CH}_{3} \mathrm{I}\right.$ was reacted on a solid phase extraction cartridge containing L-homocysteine thiolactone solution in ethanol, synthesizing $\left[{ }^{11} \mathrm{C}\right] \mathrm{MET}$ via the S-methylation of L-homocysteine in the presence of a potassium hydroxide base. After neutralization with $1 \mathrm{~N} \mathrm{HCl}$, the $\left[{ }^{11} \mathrm{C}\right] \mathrm{MET}$ was filtered through $0.22 \mu \mathrm{m}$ filters. Via the analytical HPLC system, we confirmed the prepared $\left[{ }^{11} \mathrm{C}\right] \mathrm{MET}$ 's radiochemical purity was above $95 \%$.

We performed the PET with a dedicated PET/CT scanner by GE Medical Systems (Discovery ST, GE Medical Systems, Milwaukee, WI, USA), with a spatial resolution of $5.0 \mathrm{~mm}$ (full width at half maximum) and slice thickness of $3.27 \mathrm{~mm}$. Patients were placed in the scanner such that slices parallel to the orbitomeatal line could be obtained. We intravenously injected patients with ${ }^{11} \mathrm{C}$-MET during a fasting period, at $7 \mathrm{MBq} / \mathrm{kg}$. For attenuation correction, we acquired a non-contrast-enhanced, low-dose CT scan and then began the $10 \mathrm{~min}$ emission scan $20 \mathrm{~min}$ after the injection. We reconstructed the images in the form of transaxial images of 256x256x98 anisotropic voxels (the voxel size was $1.17 \mathrm{~mm} \mathrm{x}$ $1.17 \mathrm{~mm} \times 3.27 \mathrm{~mm}$ ) with OSEM (ordered subset expectation maximization: iteration, 5; subset, 32) and used CT images for attenuation correction of the PET images.

Magnetic resonance imaging. All MR images were obtained using a 1.5-T (Signa Excite Twin Speed, GE Medical Systems, Milwaukee, WI, USA) whole-body MR scanner, with an acquisition time of $\sim 3 \mathrm{~min}$.

Image analysis. After obtaining the PET data, we registered the PET image on contrast-enhanced, T1-weighted standard anatomical MRI images, using normalized mutual information from the Leksell Gamma Plan 8.3.1 image registration software (Elekta Instrument AB, Stockholm, Sweden). We manually placed the regions of interest (ROIs) and the contralateral grey matter in the axial plane. The maximal standardized uptake value (SUVmax) was calculated over the ROI of each targeted lesion. The tumor-to-normal tissue $(\mathrm{T} / \mathrm{N})$ ratio was calculated by dividing the SUVmax of the lesion by the SUVmean of the contralateral gray matter.

Pathologic reviews and immunohistochemical staining. Tumor samples, obtained during surgery, were formalin-fixed and paraffin-embedded for the histological studies. Two independent neuropathologists re-evaluated each histological diagnosis and graded it according to the 2007 WHO classification (5). We compared the histopathologic examinations between radiologically different targets (Fig. 1B and D). The neuropathologists examined the pathologic specimens for atypism (positive/negative), mitosis (positive/negative), endothelial proliferation (positive/negative) and necrosis (positive/negative). We estimated the number of endothelial proliferations per $\mathrm{mm}^{2}$ and the cell density, depending on the necrotic extent: (grade 1) cystic fluid, (grade 2) tumor cells with necrosis $\geq 95 \%$, (grade 3 ) tumor cells with $50 \% \leq$ necrosis $<95 \%$, (grade 4) tumor cells with $25 \% \leq$ necrosis $<50 \%$, (grade 5) tumor cells with necrosis $<25 \%$ or (grade 6 ) tumor cells with focal necrosis.

For the immunohistochemical staining, we excluded specimens having over $50 \%$ necrosis and formalin-fixed and paraffin-embedded the remaining specimens, cutting them to a thickness of $5 \mu \mathrm{m}$. In the deparaffinized sections, endogenous peroxidase was blocked with $3 \% \mathrm{H}_{2} \mathrm{O}_{2}$ in methanol. We carried out the antigen retrieval for $30 \mathrm{~min}$, in a pressure cooker with Tris buffer and blocked non-specific binding for $10 \mathrm{~min}$, using protein-blocking buffer. Sections were washed in phosphatebuffered saline (PBS) and incubated overnight with anti-human L-type amino acid transporter 1 (LAT1) antibody (dilution: 1:400, clone 4D9, Trans Genic, Inc., Kobe, Japan), human Ki-67 antibody (dilution: 1:100, M7240, Dako) and Von Villebrand factor (dilution: 1:50, Clone F8/86, Dako), at $4^{\circ} \mathrm{C}$. The samples were then incubated with a secondary antibody (biotinylated link) for $10 \mathrm{~min}$, with streptavidin-HRP for $10 \mathrm{~min}$, and then with diaminobenzidine (DAB), which was used as a chromogen. All chemicals were obtained from the LSAB system (DakoCytomation; Dako, Glostrup, Denmark). Counter-staining was performed with Mayer's hematoxylin (Fig. 2).

We semi-quantitatively evaluated LAT1's immunopositivity by estimating the fraction of positive cells, regarding a level $<5 \%$ as negative expression (grade 1 ), a level $<50 \%$ as a moderate degree of expression (grade 2) and a level of $\geq 50 \%$ as a high degree of expression (grade 3 ). To measure each glioma's microvessel density (MVD), we used the method described by Zhen et al and Leon et al $(12,13)$. Briefly, in areas of the most intense neovascularization, we performed individual microvessel counts at x200 magnification (equivalent to $0.7386 \mathrm{~mm}^{2}$ ). Any endothelial cell or endothelial cell cluster was considered as a single countable microvessel. MVD was expressed as the absolute number of microvessels per x 200 field for each case. We also counted the Ki-67 labeled cells and calculated the percentage of Ki-67 labeled cells within the observed field, regarding a level $<5 \%$ as grade 1 , a $>5 \%$ to $<25 \%$ as grade 2 , a $>25 \%$ to $<50 \%$ as grade 3 , and a level of $\geq 50 \%$ as grade 4 .

Statistical analysis. Statistical analysis was performed with the SPSS software program (version 18.0 for Windows; SPSS, Inc., Chicago, IL, USA). We used multiple linear regression to analyze the enhancement, cell density, microvessel density, immunopositivity of LAT1, Ki-67 LI and the number of endothelial proliferations as the correlating factors of the $\mathrm{T} / \mathrm{N}$ ratio. A P-value of $<0.05$ was considered statistically significant.

\section{Results}

Pathologic analysis corresponding to active or necrotic lesions. Pathologic analysis is summarized in Table I. Male to female ratio was 6:6 and median age was 65 years (range: 55-77 years). The final diagnosis of all specimens was 

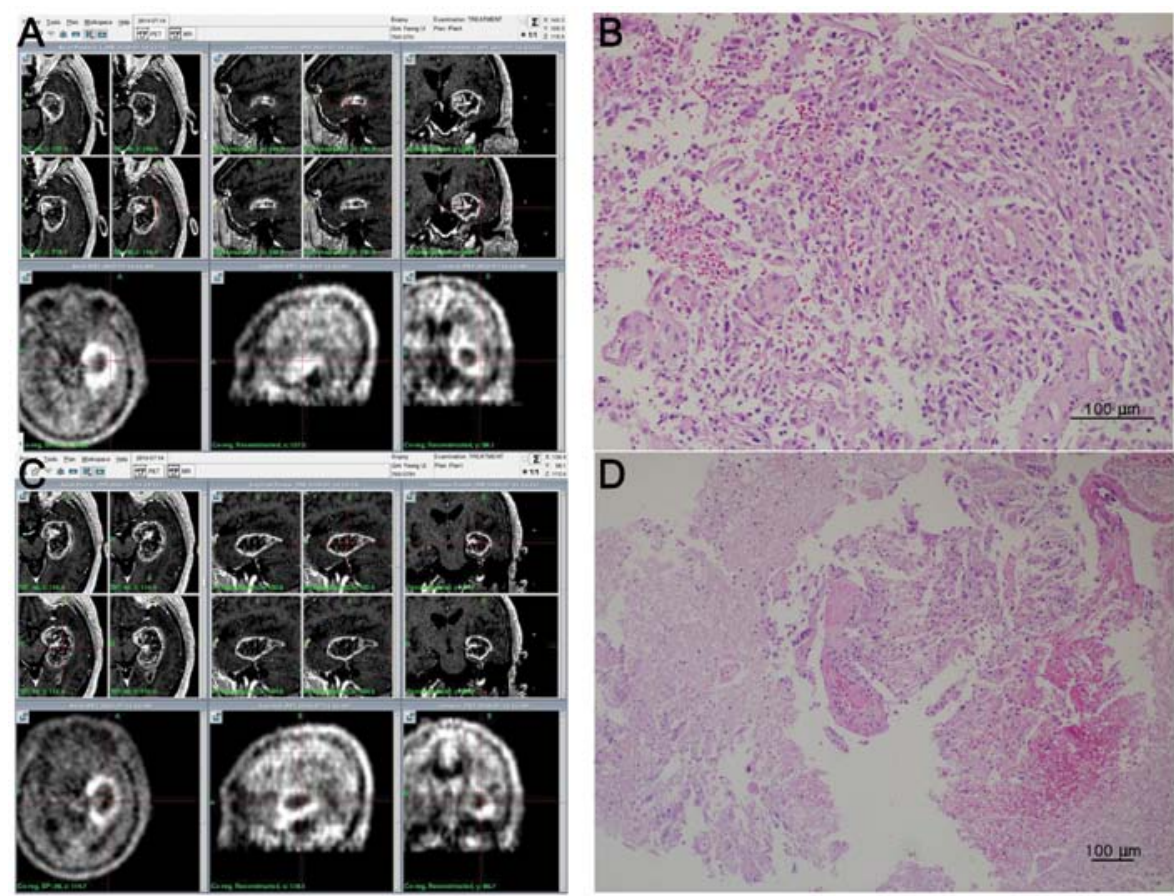

Figure 1. Radiologic targets (red cross) for biopsy with Leksell Gamma Plan images. (A) MR contrast-enhanced area for active tumor and ${ }^{11} \mathrm{C}$-methionine-PET image (T/N ratio=2.91). (B) Pathologic review for target A: atypism (positive), mitosis (positive), endothelial proliferation (positive) and necrosis (positive). (C) MR non-enhanced area for necrosis and ${ }^{~}{ }^{11} \mathrm{C}$-methionine-PET image ( $\mathrm{T} / \mathrm{N}$ ratio=0.68). (D) Pathologic review for target $\mathrm{C}$ : atypism (negative), mitosis (negative), endothelial proliferation (positive) and necrosis (positive).

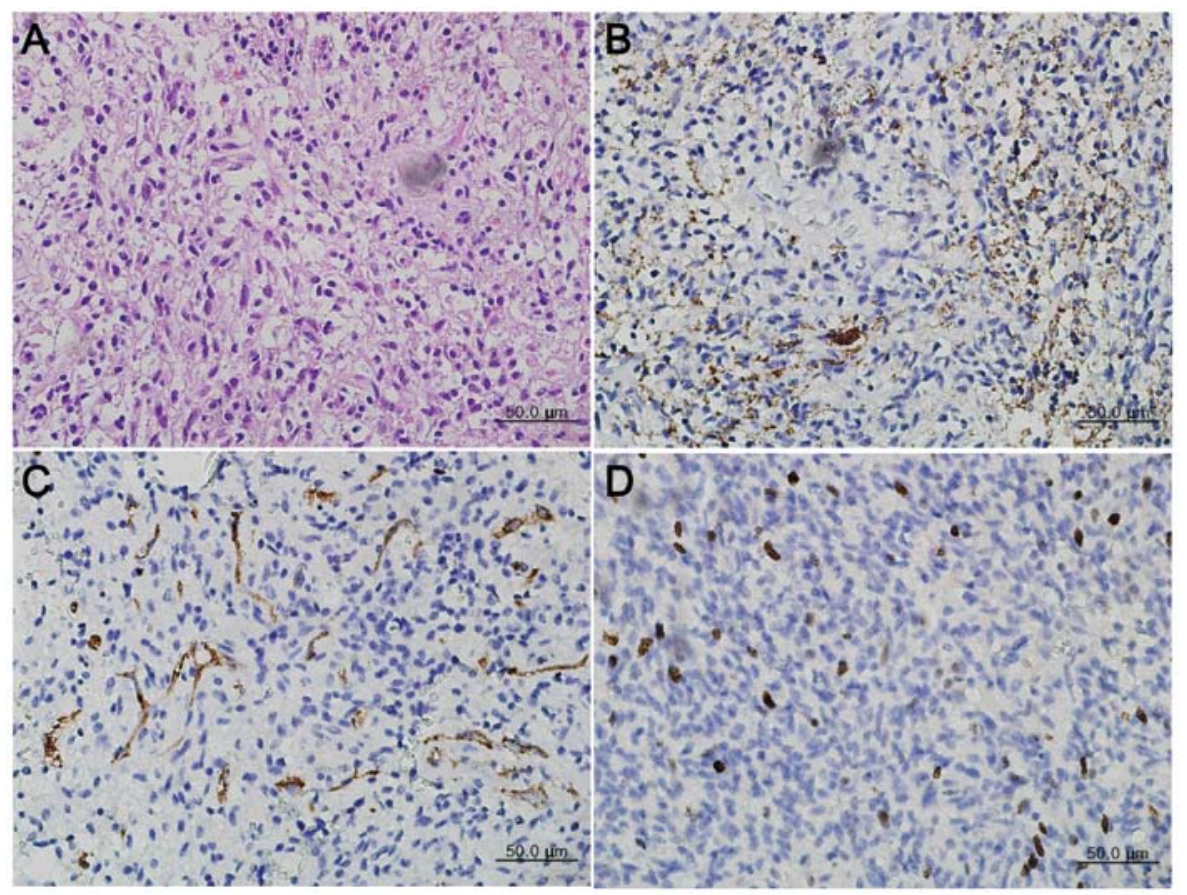

Figure 2. Immunohistochemical staining for L-type amino acid transporter 1 (LAT1), Von Villebrand factor and Ki-67 antigen. (A) Hematoxylin and eosin staining for glioblastoma. (B) Immunohistostaining for LAT1 (grade 2). (C) Immunohistochemical staining for Von Willebrand factor (81.2/mm²). (D) Ki-67 antigen (grade 2).

glioblastoma as below criteria (atypism/mitosis/endothelial proliferation/necrosis).

When we chose the MR-enhanced active lesions as targets, in a total of 12 patients, we diagnosed eight patients with glioblastoma, three with anaplastic astrocytoma and one with astrocytoma. When we chose only one enhanced lesion for biopsy, the glioblastoma diagnosis failure rate was 33.3\% (4/12 patients). For the MR non-enhanced necrotic lesions, in a total of 10 patients, we diagnosed 6 patients with glioblastoma, found 2 patients had necrotic tissue at $>95 \%$ and found 2 had 
Table I. Pathologic analysis corresponding to active or necrotic lesions.

\begin{tabular}{|c|c|c|c|c|c|c|}
\hline & & MR enhanced active lesion & & MR non-enhanced necrotic lesion & & \\
\hline No. & Age/Gender & $\begin{array}{l}\text { Atypism/Mitosis/Endothelial } \\
\text { proliferation/Necrosis }\end{array}$ & $\mathrm{Dx}^{\mathrm{a}}$ & $\begin{array}{l}\text { Atypism/Mitosis/Endothelial } \\
\text { proliferation/Necrosis }\end{array}$ & Dx & $\begin{array}{c}\text { Final } \\
\text { Dx }\end{array}$ \\
\hline 1 & $49 / \mathrm{F}^{\mathrm{b}}$ & $+/+/-/-$ & $\mathrm{AA}^{\mathrm{d}}$ & $+/+/+/+$ & $\mathrm{GM}^{\mathrm{e}}$ & GM \\
\hline 2 & $72 / \mathbf{M}^{\mathrm{c}}$ & $+/+/+/+$ & GM & $+/+/+/+$ & GM & GM \\
\hline 3 & $76 / \mathrm{M}$ & $-/-/+/-$ & $\mathrm{LGG}^{\mathrm{f}}$ & $+/-/+/+$ & GM & GM \\
\hline 4 & $58 / \mathrm{M}$ & $+/+/-/-$ & AA & $-/-/+/+$ & Only necrosis & GM \\
\hline 5 & $55 / \mathrm{M}$ & $+/+/+/+$ & GM & $+/+/+/-$ & GM & GM \\
\hline 6 & $76 / \mathrm{F}$ & $+/+/-/-$ & AA & $+/-/+/+$ & GM & GM \\
\hline 7 & $77 / \mathrm{M}$ & $+/-/+/+$ & GM & $+/-/+/+$ & GM & GM \\
\hline 8 & $59 / \mathrm{F}$ & $+/+/+/+$ & GM & $-/-/-/+$ & Only necrosis & GM \\
\hline 9 & $58 / \mathrm{F}$ & $+/+/+/-$ & GM & Cystic fluid & Few tumor cells & GM \\
\hline 10 & $78 / \mathrm{F}$ & $+/-/+/+$ & GM & Cystic fluid & Few tumor cells & GM \\
\hline 11 & $68 / \mathrm{M}$ & $+/+/+/-$ & GM & & & GM \\
\hline 12 & $59 / \mathrm{F}$ & $+/+/+/-$ & GM & & & GM \\
\hline
\end{tabular}

adiagnosis; ${ }^{\mathrm{a}} \mathrm{female} ;{ }^{\mathrm{c}}$ male; ${ }^{\mathrm{d}}$ anaplastic astrocytoma; ${ }^{\mathrm{e}}$ glioblastoma; ${ }^{\mathrm{f}}$ low grade glioma.

Table II. Statistical analysis: relating factors of $\mathrm{T} / \mathrm{N}$ ratio.

\begin{tabular}{|c|c|c|}
\hline $\mathrm{T} / \mathrm{N}$ ratio related factors & No. of patients & P-value \\
\hline \multicolumn{3}{|l|}{ Cell density } \\
\hline Grade 1 : cystic fluid & 2 & 0.002 \\
\hline Grade 2: tumor cells with necorsis $\geq 95 \%$ & 2 & \\
\hline Grade 3: tumor cells with $50 \% \leq$ necrosis $<95 \%$ & 1 & \\
\hline Grade 4 : tumor cells with $25 \% \leq$ necrosis $<50 \%$ & 3 & \\
\hline Grade 5: tumor cells with necrosis $<25 \%$ & 4 & \\
\hline Grade 6: tumor cells with focal necrosis & 10 & \\
\hline \multicolumn{3}{|l|}{ LAT1 } \\
\hline Grade $1:<5 \%$ & 8 & 0.032 \\
\hline Grade $2: 5-50 \%$ & 7 & \\
\hline Grade $3:>50 \%$ & 2 & \\
\hline MVD $^{a}$ & & 0.057 \\
\hline $\mathrm{EP}^{\mathrm{b}}$ & & 0.24 \\
\hline \multicolumn{3}{|l|}{ Ki-67 LI } \\
\hline Grade $1:<5 \%$ & 5 & 0.741 \\
\hline Grade $2: 5-25 \%$ & 6 & \\
\hline Grade $3: 25-50 \%$ & 2 & \\
\hline Grade $4:>50 \%$ & 4 & \\
\hline
\end{tabular}

${ }^{\mathrm{a}}$ Microvessel density (microvessels $/ \mathrm{mm}^{2}$ ); ${ }^{\mathrm{b}}$ endothelial proliferations $/ \mathrm{mm}^{2}$.

cystic fluid. Four patients with necrotic tissue and cystic fluid did not receive confirmation diagnoses because they did not show enough tumor cells. The diagnostic failure rate was thus $40 \%$ (4/10 patients) for biopsy of one non-enhanced lesion. Patient number 4 received a final diagnosis of glioblastoma, reflecting the pathologic features of atypism, endothelial proliferation and necrosis in both lesions.
Pathologic features depending on ${ }^{11} \mathrm{C}$-methionine uptake and LAT-1 localization. Table II summarizes the pathologic features depending on ${ }^{11} \mathrm{C}$-methionine uptake. The cell densities were at grade 1 (cystic fluid) in 2, grade 2 (tumor cells with necrosis $\geq 95 \%$ ) in 2 , grade 3 (tumor cells with $\leq 50 \%$ to necrosis $<95 \%$ ) in 1 , grade 4 (tumor cells with $\geq 25 \%$ to $<50 \%$ necrosis) in 3 , grade 5 (tumor cells with necrosis $<25 \%$ ) in 4 and 
A

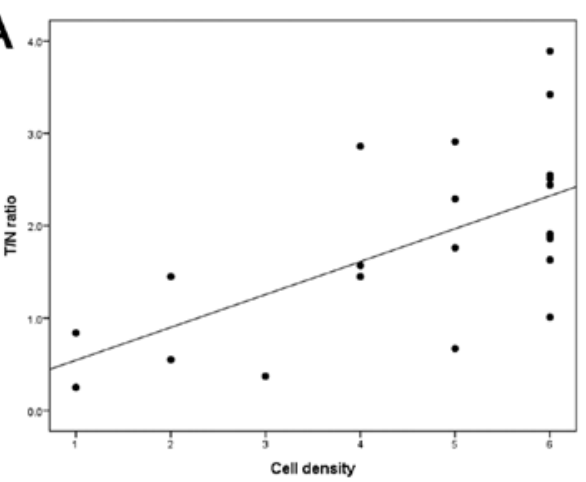

C

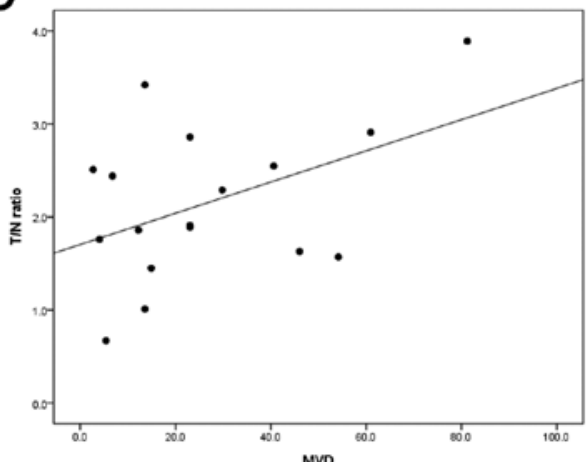

B

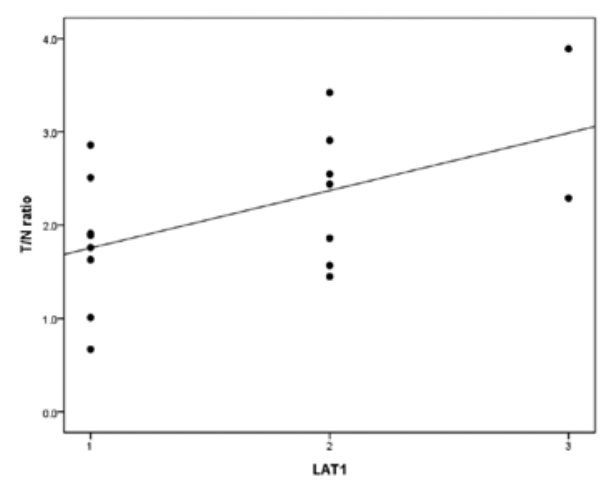

D

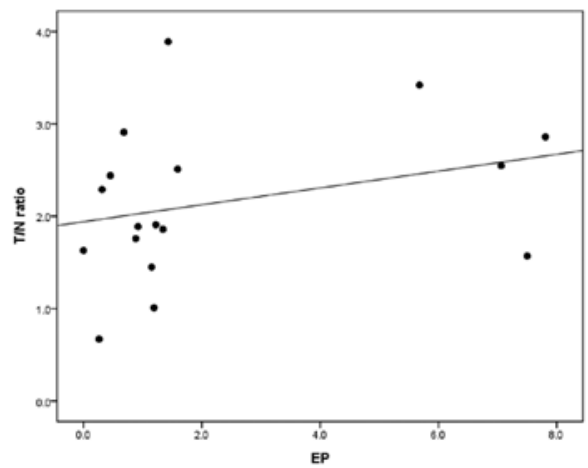

Figure 3. Statistical analysis of correlated factors, depending on the $\mathrm{T} / \mathrm{N}$ ratio. (A) Cell density correlated statistically with $\mathrm{T} / \mathrm{N}$ ratio $(\mathrm{r}=0.629, \mathrm{P}=0.002)$. (B) T/N ratio correlated statistically with LAT1 immunopositivity $(\mathrm{r}=0.271, \mathrm{P}=0.032)$. (C, D) The MVD (microvessels $/ \mathrm{mm}^{2}$ ) and the number of endothelial proliferations $/ \mathrm{mm}^{2}$ showed no positive correlations with $\mathrm{T} / \mathrm{N}$ ratio $(\mathrm{r}=0.208, \mathrm{P}=0.057$ and $\mathrm{r}=0.091, \mathrm{P}=0.24$, respectively).
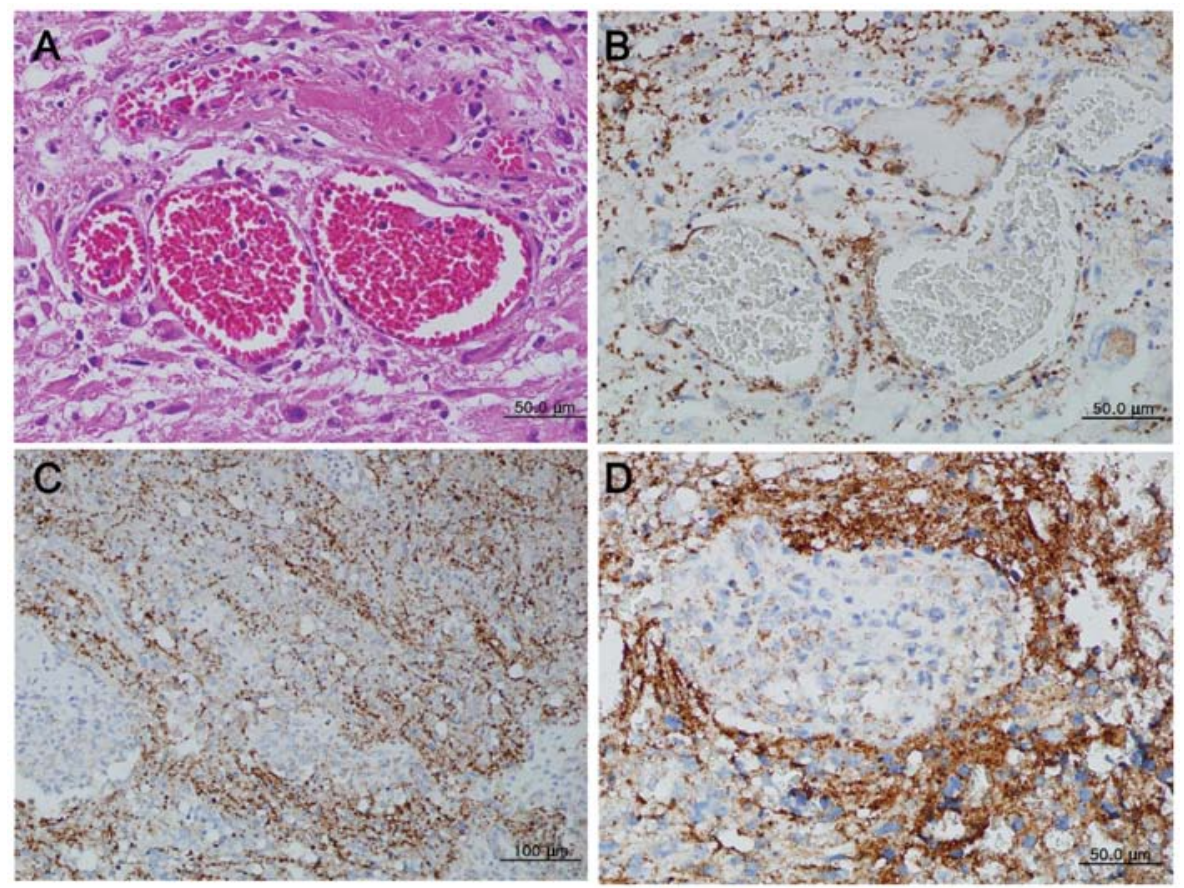

Figure 4. Localization of LAT1. (A) Hematoxylin and eosin staining for glioblastoma. (B) Localization of LAT1 in the endothelium on vessels and cytoplasm in tumor cells. (C, D) Most outside endothelial cells and near tumor cells showed LAT immunopositivity in the areas of endothelial proliferation.

grade 6 (tumor cells with focal necrosis) in 10. We statistically correlated the cell density, depending on the necrotic extent, with the $\mathrm{T} / \mathrm{N}$ ratio $(\mathrm{r}=0.629, \mathrm{P}=0.002$; Fig. $3 \mathrm{~A})$. The LAT1 immunopositivity showed a negative expression (grade 1) in 8 , a moderate degree of expression (grade 2) in 7 and a high degree of expression (grade 3 ) in 2 . There was a statistical 
correlation between the T/N ratio and LAT1 immunopositivity $\left(\mathrm{r}=0.271, \mathrm{P}=0.032\right.$; Fig. 3B). The MVD (microvessels $/ \mathrm{mm}^{2}$ ) and the number of endothelial proliferations $/ \mathrm{mm}^{2}$ failed to show a positive correlation with $\mathrm{T} / \mathrm{N}$ ratio $(\mathrm{r}=0.208, \mathrm{P}=0.057$ and $\mathrm{r}=0.091, \mathrm{P}=0.24$, respectively; Fig. $3 \mathrm{C}$ and D). A Ki-67 labeling index appeared in 5 at level $<5 \%$ (grade 1), 6 at $>5 \%$ to $<25 \%$ (grade 2), 2 at $>25 \%$ to $<50 \%$ (grade 3 ) and 4 at level of $\geq 50 \%$ (grade 4 ), but it showed no statistical correlation with $\mathrm{T} / \mathrm{N}$ ratio $(\mathrm{r}=0.007, \mathrm{P}=0.741)$.

On the immunohistochemical staining, the LAT1 localized in the endothelium in vessels and the cytoplasm in tumor cells. In the areas with endothelial proliferation, most outside endothelial cells and near tumor cells showed immunopositivity (Fig. 4).

\section{Discussion}

MRI-guided stereotactic biopsies are performed to identify the nature of an intracranial tumor. Because gliomas are histologically heterogeneous, pathological examinations of stereotactic samples do not always yield their actual grade and extent. Greene et al reported that, in gliomas, the diagnostic yield of CT-guided stereotactic biopsy was 56,67 and $36 \%$ for biopsies performed in the center of the lesion, the enhancing margin, and the hypodense periphery, respectively (14). Furthermore, serial biopsies are needed to minimize the diagnostic failure risk, which reportedly ranges from 1.8 to $7.2 \%(15,16)$. To get the essential pathologic features of glioblastomas, such as their endothelial proliferation and/or necrosis, we chose enhanced and non-enhanced lesions corresponding to active and necrotic lesions, respectively. The degree of ${ }^{11} \mathrm{C}$-methionine uptake was expressed as a ratio to control brain tissue ( $\mathrm{T} / \mathrm{N}$ ratio) and also analyzed along with the various pathologic findings.

First, we analyzed the data comparing MR enhanced lesions and non-enhanced lesions. When we considered the enhanced lesions, we achieved a $66.6 \%$ (8 patients out of 12) diagnostic rate, even when all lesions were glioblastomas. Three patients diagnosed with anaplastic astrocytoma each showed two components out of the elements atypism, mitosis, endothelial proliferation and necrosis. One patient showed the features of a low-grade glioma, which was perhaps a marginal tumor area. In biopsies of the non-enhanced areas, we had $60 \%$ (6 patients out of 10) glioblastoma diagnostic rates. Two patients had more than $95 \%$ necrotic tissue, which meant we could not confirm their diagnoses. Two patients had yellowish cystic fluid containing a few tumor cells, which we could not analyze. When we examined both types of lesions, we got a final diagnosis of glioblastoma in all the cases. One patient had anaplastic astrocytoma in the enhanced portion and necrosis only in the non-enhanced portion. If we combined these features, we could achieve the correct final diagnosis. Therefore, we suggest that biopsies for different targets are needed to minimize the risk of diagnostic failure, and that, in glioblastoma, clinicians can achieve a final diagnosis using biopsies of active and necrotic lesions, even when the lesion's regional heterogeneity provides a serious challenge.

The ${ }^{11} \mathrm{C}$-methionine PET imaging technique provides functional data that are independent of CT or MRI anatomical images and, in brain tumor cases, giving important information on both histological malignancy and tumor viability (10).
${ }^{11} \mathrm{C}$-methionine crosses the intact BBB and the tumor cells incorporate it via the neutral amino acid transport system $(17,18)$. Reportedly, this system, the large neutral amino acid transporter 1 (LAT1) is expressed strongly in several tumor cell lines and in tumor endothelial membrane, and it shows a significant correlation with ${ }^{11} \mathrm{C}$-methionine uptake in human gliomas $(6,19-21)$. Several studies suggest that the degree of ${ }^{11} \mathrm{C}$-methionine uptake correlates with tumor cell density, proliferative potential, and microvessel density and area in gliomas (8-11). We evaluated each correlated factor according to the ${ }^{11} \mathrm{C}$-methionine uptake. The $\mathrm{T} / \mathrm{N}$ ratio showed a statistical correlation with cell density depending on the degree of necrosis and the LAT1 $(\mathrm{P}=0.002)$. To show the ${ }^{11} \mathrm{C}$-methionine uptake localization, we performed immunohistochemical staining on the LAT1. Immunopositivity correlated statistically with $\mathrm{T} / \mathrm{N}$ ratio $(\mathrm{P}=0.032)$ and LAT1 appeared localized in the endothelium of vessels and in the cytoplasm of tumor cells. One study has depicted the localized LAT1 pattern (21). LAT1 expression appeared in the tumor vascular endothelium and tumor cytoplasm and, regarding endothelial proliferations, all layers of vessels showed this immunopositivity (16). Our study showed a similar pattern of expression. However, in endothelial proliferation, most outside endothelial cells and tumor cells near these areas showed a strong positivity for LAT1.

We suggest that multiple stereotactic biopsies of active tumor and necrosis could provide the diagnostic yield in glioblastoma. The ${ }^{11} \mathrm{C}-$-methionine uptake mostly reflected cell densities depending on the degree of necrosis.

\section{Acknowledgements}

This study was supported by a grant (CRI11047-1) from the Chonnam National University Hospital Research Institute of Clinical Medicine.

\section{References}

1. Levivier M, Goldman S, Pirotte B, et al: Diagnostic yield of stereotactic brain biopsy guided by positron emission tomography with $\left[{ }^{18} \mathrm{~F}\right]$ fluorodeoxyglucose. J Neurosurg 82: 445-452, 1995.

2. Glantz MJ, Burger PC, Herndon JE II, et al: Influence of the type of surgery on the histologic diagnosis in patients with anaplastic gliomas. Neurology 41: 1741-1744, 1991.

3. Chandrasoma PT, Smith MM and Apuzzo ML: Stereotactic biopsy in the diagnosis of brain masses: comparison of results of biopsy and resected surgical specimen. Neurosurgery 24: 160-165, 1989.

4. Brucher JM: Neuropathological diagnosis with stereotactic biopsies. Possibilities, difficulties and requirements. Acta Neurochir (Wien) 124: 37-39, 1993.

5. Cavenee WK FF and Nagane M: Astrocytic tumors. In: World Health Organization Classification of Tumours: Pathology and Genetics: Tumours of the Nervous System. Kleihues P and Cavenee WK (eds). IARC Press, Lyon, pp27-29, 2000.

6. Bergstrom M, Lundqvist $\mathrm{H}$, Ericson $\mathrm{K}$, et al: Comparison of the accumulation kinetics of L-(methyl- $\left.{ }^{11} \mathrm{C}\right)$-methionine and D-(methyl- $\left.{ }^{11} \mathrm{C}\right)$-methionine in brain tumors studied with positron emission tomography. Acta Radiol 28: 225-229, 1987.

7. Kanai Y, Segawa H, Miyamoto K, Uchino H, Takeda E and Endou H: Expression cloning and characterization of a transporter for large neutral amino acids activated by the heavy chain of 4F2 antigen (CD98). J Biol Chem 273: 23629-23632, 1998.

8. Chung JK, Kim YK, Kim SK, et al: Usefulness of ${ }^{11} \mathrm{C}$-methionine PET in the evaluation of brain lesions that are hypo- or isometabolic on ${ }^{18}$ F-FDG PET. Eur J Nucl Med Mol Imaging 29: 176-182, 2002. 
9. Kato T, Shinoda J, Nakayama N, et al: Metabolic assessment of gliomas using ${ }^{11} \mathrm{C}$-methionine, $\left[{ }^{18} \mathrm{~F}\right]$ fluorodeoxyglucose, and ${ }^{11} \mathrm{C}$-choline positron-emission tomography. Am J Neuroradiol 29: 1176-1182, 2008

10. Nojiri T, Nariai T, Aoyagi M, et al: Contributions of biological tumor parameters to the incorporation rate of L: -[methyl-(11)C] methionine into astrocytomas and oligodendrogliomas. J Neurooncol 93: 233-241, 2009.

11. Okita Y, Kinoshita M, Goto T, et al: (11)C-methionine uptake correlates with tumor cell density rather than with microvessel density in glioma: a stereotactic image-histology comparison. Neuroimage 49: 2977-2982, 2010.

12. Zhen HN, Zhang X, Hu PZ, et al: Survivin expression and its relation with proliferation, apoptosis, and angiogenesis in brain gliomas. Cancer 104: 2775-2783, 2005.

13. Leon SP, Folkerth RD and Black PM: Microvessel density is a prognostic indicator for patients with astroglial brain tumors. Cancer 77: 362-372, 1996.

14. Greene GM, Hitchon PW, Schelper RL, Yuh W and Dyste GN: Diagnostic yield in CT-guided stereotactic biopsy of gliomas. J Neurosurg 71: 494-497, 1989.

15. Kelly PJ, Daumas-Duport C, Kispert DB, Kall BA, Scheithauer BW and Illig JJ: Imaging-based stereotaxic serial biopsies in untreated intracranial glial neoplasms. J Neurosurg 66: 865-874, 1987.
16. Thomas DG and Nouby RM: Experience in 300 cases of CT-directed stereotactic surgery for lesion biopsy and aspiration of haematoma. Br J Neurosurg 3: 321-325, 1989.

17. Oldendorf WH and Szabo J: Amino acid assignment to one of three blood-brain barrier amino acid carriers. Am J Physiol 230: 94-98, 1976.

18. Sanchez del Pino MM, Peterson DR and Hawkins RA: Neutral amino acid transport characterization of isolated luminal and abluminal membranes of the blood-brain barrier. J Biol Chem 270: 14913-14918, 1995.

19. Langen KJ, Muhlensiepen H, Holschbach M, Hautzel H, Jansen $P$ and Coenen HH: Transport mechanisms of 3-[ $\left.{ }^{123} \mathrm{I}\right]$ iodo- $\alpha-$ methyl-L-tyrosine in a human glioma cell line: comparison with $\left[{ }^{3} \mathrm{H}\right]$ methyl]-L-methionine. J Nucl Med 41: 1250-1255, 2000.

20. Wienhard K, Herholz K, Coenen HH, et al: Increased amino acid transport into brain tumors measured by PET of L- $\left(2-{ }^{18} \mathrm{~F}\right)$ fluorotyrosine. J Nucl Med 32: 1338-1346, 1991.

21. Okubo S, Zhen HN, Kawai N, Nishiyama Y,Haba R and Tamiya T: Correlation of L-methyl-11C-methionine (MET) uptake with L-type amino acid transporter 1 in human gliomas. J Neurooncol 99: $217-225$. 